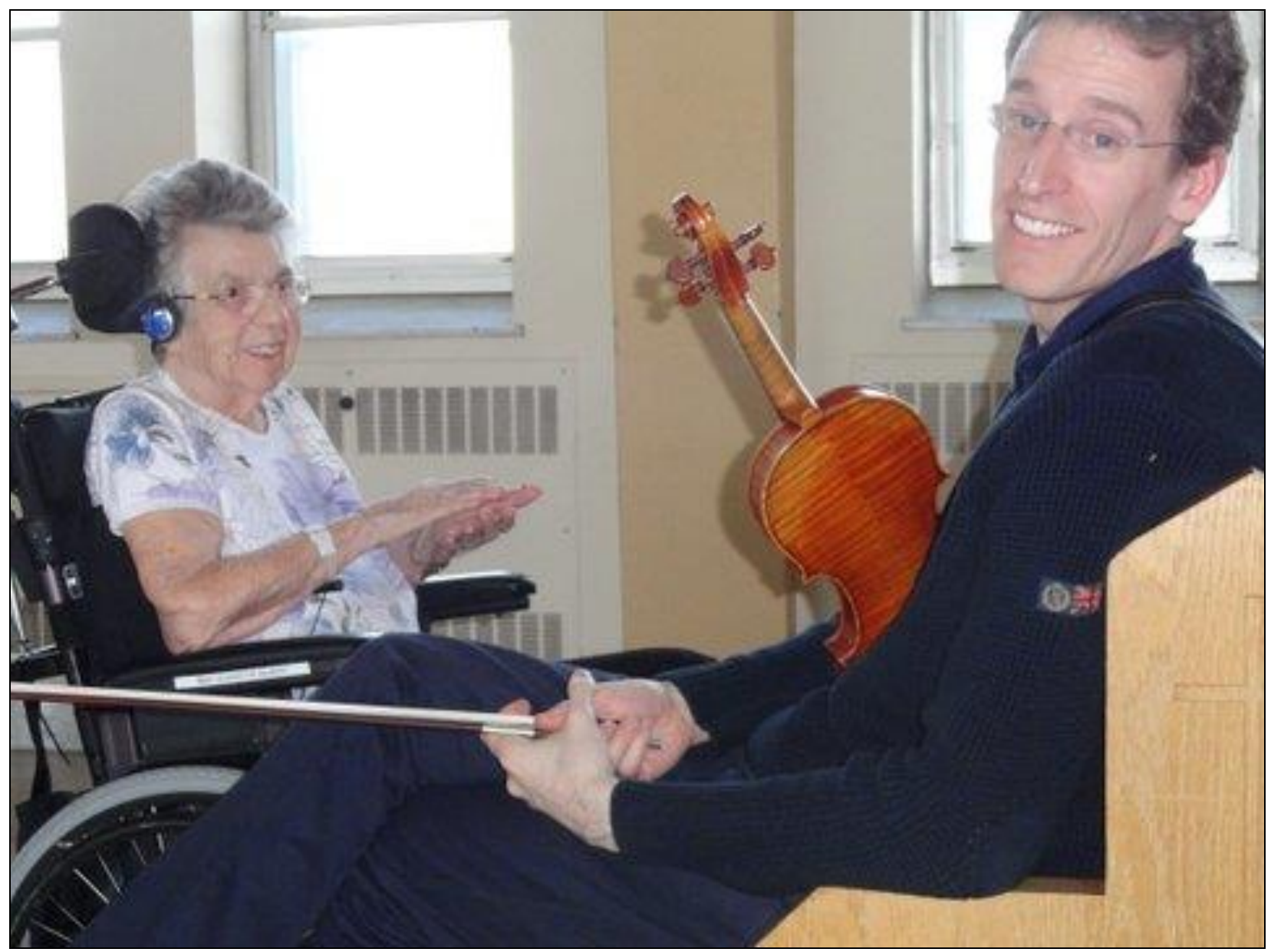

Photo credit: Guillaume Tardif

\title{
Precious Smile
}

Guillaume Tardif

University of Alberta, Canada

This picture reminds me of a visit to my grandmother (left), who died quietly a few days ago. I am to play tomorrow in her memory at a church in Quebec City, a few meters away from where she lived most of her life, raising her five kids. During Christmas break last year, my devoted father took me down to the hospital and asked to bring my violin along: we rolled the chair down to the hospital's chapel, and I played a few things for her, to her apparent enjoyment. She always warmly encouraged my music studies since childhood, though she had very little background in music; family gatherings usually involved my showing new pieces, and I often went to tell her about my concert adventures and travels (she had never taken the plane, and rarely left the neighborhood). The last years were years of residence care, her husband had passed away in a similar fashion, gradually closing up to the world, with failing eyes, ears, limbs, and memory. A bit of music-making, simple as it was, seemed to bring some of her old self back for a few seconds - and the camera captured an instant of it. 